\title{
The Importance of Configuration for Understanding Birth Trauma
}

\author{
VV Vlasyuk* \\ Department of Forensic Medicine, Russia
}

*Corresponding author: VV Vlasyuk, Department of Forensic Medicine, S. M. Kirov Military Medical Academy, Lebedev str., 6, 194044, St Petersburg, Russia

\begin{abstract}
ARTICLE INFO
Received: 崀 January 18, 2021

Published: 㓞 January 29, 2021

Citation: VV Vlasyuk. The Importance of Configuration for Understanding Birth Trauma. Biomed J Sci \& Tech Res 33(3)-

ABSTRACT

The relationship between the configuration (molding) of the fetal head and birth traumatic injuries is considered. It is shown that the configuration includes a complex of changes in the skull and brain of a compensatory-adaptive nature. The mechanisms are considered that, in a pathological configuration, lead to various traumatic injuries. To understand the cause of birth trauma, it is necessary to explain why the physiological configuration becomes pathological. The importance of control over the state of configuration during childbirth is emphasized.
\end{abstract} 2021. BJSTR. MS.ID.005414.

Keywords: Birth Trauma; Configuration (molding); Compression Hypoxic Birth Trauma; Birth Traumatic Injuries; Degrees of Configuration
Abbreviations: TC: Tentorium Cerebelli, SDH: Subdural Hemorrhage, LMH: Leptomeningeal Hemorrhage, SPH: Subpial Hemorrhage, SAH: Subarachnoid Hemorrhage, ICH: Intracerebral Hemorrhage, $\mathrm{CH}$ : Cerebellar Hemorrhage, ME: Multicystic Encephalomalacia

\section{Mini Review}

Configuration (molding) is an evolutionarily formed process that ensures the adaptation of the size and shape of the head to the birth canal of the mother and also prevents birth trauma (BT) to the mother and fetus. It is known that the configuration prevents birth trauma [1], but the pronounced configuration leads to traumatic injuries to the skull and brain. A pronounced head configuration is observed with cephalopelvic disproportion, prolonged or dysfunctional labor, difficult delivery, operative delivery (vacuum extraction and forceps delivery), excessive use of oxytocin, excessive uterine contractions and other reasons. However, how do these conditions and complications of childbirth lead to birth damage? All causes are mediated by head configuration. The configuration of the head is a mediated link in the interaction of pathology during childbirth and birth injuries, so it can explain the cause and mechanisms of these injuries. The configuration can be diagnosed by vaginal examination and sonography during labor. All causes of obstructed labor are mediated by configuration mechanisms that both neutralize the effect of these causes, and can become pathological for the fetus, leading to birth traumatic injuries. That is, compensation mechanisms become insufficient to prevent traumatic injuries.

\section{Types and Degree of Configuration}

It is impossible to understand the reason and warn BT if you do not know the state of the fetal head configuration during labor. The first and required knowledge is the degree of configuration that can be determined. You can determine the type of pathological configuration. There is the following classification of degrees of configuration [2,3]: none $(0)=$ bones normally separated; $+=$ bones touching; ++ = bones overlapping but easily separated with digital pressure; +++ = bones overlapping and not separable with digital pressure. I distinguish the following classification of degrees of configurations [4,5]: 1 (light) - overlapping of bones over one of sutures, 2 (moderate) - overlapping of bones within 2-3 sutures, 3 (expressed) - overlapping of bones over 4-5 sutures. It is believed that when traction with obstetric forceps and a vacuum extractor with a moderate and pronounced configuration increases the risk of birth damage to the fetus [3]. Our studies have shown that with an increase in the degree of configuration, the frequency of many brain lesions, primarily leptomeningeal hemorrhages, increases [4]. 
Clinical studies have shown that with the second and third degrees of the configuration of the head, early deceleration is observed: with the second degree, the appearance of early decelerations, and with the third degree, the appearance of early and sporadic decelerations [6]. Light and moderate configurations do not lead to pathological changes but expressed (pathological) degree leads to compression hypoxia of the fetal brain [7] and birth trauma. Clinical and experimental studies have shown that head compression leads to deceleration of cardiac activity [8-10]. When does a pathological head configuration occur? In 3 situations. When it is 1) excessive, 2) rapid and 3) asymmetrical [4,5]. These are three types of pathological configuration of the fetal head.

\section{What Does the Head Configuration Depend on?}

The nature of the configuration depends on:

1. The course of childbirth, the forces acting during childbirth,

2. The state of the birth canal and the mother's pelvis,

3. Configurability of the fetal head (the ability to undergo configuration, the ability to adapt to the size of the birth canal). The concept of "configurability" was introduced by D. Muller [11].

The configurability of the head depends on:

1. The degree of ossification of the skull bones, their density and elasticity,

2. The gestational age,

3. The size of the sutures and fontanelles,

4. The presence of anomalies in the development of the skull.

The cause of BT can be recognized by understanding the configuration of the fetal head. Configuration is the key to understanding BT. Physiological configuration with its mechanisms is the scientific basis of BT.

\section{What Happens When the Head is Configured?}

During the configuration, the following changes occur on the part of the skull and brain:
1. Displacements and various types of overlapping of the skullcap bones.

2. Changes in the shape of the head and its diameters during labor.

3. Stretching of the cerebellar tentorium, fax and bridging veins.

4. Stretching of various structures of the brain.

5. Narrowing of the superior sagittal sinus.

6. Pressure of the dura mater on the surface and vessels of the brain.

7. Moving the mass of the brain inside the skull.

8. Increased intracranial pressure.

9. Reorganization of blood circulation in the tissues of the head and in the membranes of the brain.

10. Changes in blood circulation in the substance of the brain.

All these changes occur within physiological limits without harming the child. This configuration is physiological. The fetus, thanks to evolutionary adaptations [12], is able to adapt to these changes in childbirth and, after all the changes in the head, is born healthy. If these changes go beyond the boundaries of adaptive mechanisms, then a pathological configuration occurs, birth traumatic injuries and BT. With the control of these changes and knowledge of their norms, BT can be prevented.

\section{What is the Mechanism of Connection Configuration with Traumatic Injuries?}

The changes in the skull and brain described above with a pathological configuration led to various traumatic injuries. This is presented in more detail in Table 1. The described injuries can be a manifestation of both obvious birth trauma and compression hypoxia. A vacuum extractor and obstetric forceps lead to an aggravation of the pathological configuration, ruptures of the tentorium cerebelli and bridging veins, compression of the veins, sinuses, brain, SDH, LMH, venous stasis, hypoxic damage to neurons and glia and other traumatic injuries. Damage also occurs from local pressure on the head of the blades of obstetric forceps, the hands of the obstetrician (for example, in the case of removing the head during a cesarean section), the walls of the birth canal (for example, in breech presentation).

Table 1: Mechanisms of birth injuries in pathological configuration of the head.

\begin{tabular}{|c|c|c|}
\hline What Happens at Pathological Configuration & Mechanism of Birth Traumatic Injury & The Nature of the Birth Traumatic Injury \\
\hline Tension of the tentorium cerebelli (TC) and falx & Tears of TC and falx, rupture of blood vessels & Intradural hemorrhage, SDH \\
\hline Displacement of the brain mass & Displacement of the brain mass & SDH, LMH, ICH \\
\hline $\begin{array}{c}\text { Displacement of the brain mass. Pressure of the } \\
\text { dura mater on the arachnoid and pia mater. }\end{array}$ & $\begin{array}{c}\text { Friction between the dura mater and } \\
\text { arachnoid; rupture of blood vessels under the } \\
\text { pia mater }\end{array}$ & SPH, ICH, SAH \\
\hline $\begin{array}{c}\text { Displacement of the cerebellum together with } \\
\text { the brain stem into the TC hole }\end{array}$ & $\begin{array}{c}\text { Pressure of the TC edge on the superior } \\
\text { surface of the cerebellum }\end{array}$ & CH, SPH, SAH \\
\hline
\end{tabular}




\begin{tabular}{|c|c|c|}
\hline $\begin{array}{l}\text { Pressure of the bones of the skullcap on the } \\
\text { surface of the brain }\end{array}$ & $\begin{array}{l}\text { Compression of cerebral vessels, venous } \\
\text { congestion, "steps" along the sutures }\end{array}$ & $\begin{array}{l}\mathrm{LMH}, \mathrm{ICH} \text {, cerebral infarctions, ischemic changes in } \\
\text { neurons, ME }\end{array}$ \\
\hline Compression of the superior sagittal sinus & $\begin{array}{l}\text { Obstruction of venous outflow from the brain, } \\
\text { venous stasis }\end{array}$ & $\begin{array}{l}\text { Hypoxic damage to neurons and glial cells, sinus } \\
\text { thrombosis }\end{array}$ \\
\hline $\begin{array}{l}\text { Pressure of the squama of the occipital bone on } \\
\text { the cerebellum when there is pressure on the } \\
\text { occipital bone }\end{array}$ & $\begin{array}{c}\text { Compression of the cerebellum, brainstem, } \\
\text { venous congestion }\end{array}$ & $\begin{array}{c}\text { Compression of the cerebellum, brainstem, venous } \\
\text { congestion } \\
\mathrm{CH}, \mathrm{SAH}, \mathrm{ICH} \text {, crushing of cerebellar tissue, } \\
\text { osteodiastasis, detachment of squama from the } \\
\text { base }\end{array}$ \\
\hline Increased intracranial pressure & $\begin{array}{l}\text { Cerebral circulation disorders, hypoxia and } \\
\text { ischemia of brain tissue }\end{array}$ & $\begin{array}{l}\text { Hypoxic damage to neurons and glial cells, } \\
\text { infarction, venous stasis, thrombosis }\end{array}$ \\
\hline
\end{tabular}

\section{Conclusion}

To understand the birth process, it is important to know, on the one hand, not only the size of the mother's pelvis, the nature of the contractions, the dilatation of the cervix, the position of the head, etc., but, on the other hand, the process of configuration of the head. The configuration is not only the displacement of the bones of the skullcap, but also the movement of the brain inside the skull, changes in the bridging veins, the degree of tension of the cerebellar tentorium, the value of intracranial pressure, changes in blood circulation in the brain tissue, etc. Only by knowing all the changes in the skull and brain during childbirth can birth traumatic injuries be prevented. With a pathological configuration of the fetal head during childbirth, not only severe traumatic injuries (fractures, ruptures, hemorrhages) occur, but also compression hypoxic-ischemic brain damage. Since these lesions are caused by mechanical factors, they can be attributed to compression hypoxicischemic birth trauma. Conflicts of interest or any financial interest do not exist.

\section{References}

1. Issell EP (1976) Configuration of the newborn through the mechanical forces during birth and refiguration. Zbl Gynak 98(21): 1301-1306.

2. Sorbe B, Dahlgren S (1983) Some important factors in the molding of the fetal head during vaginal delivery--a photographic study. Int J Gynaecol Obstet 21(3): 205-212.

\section{ISSN: 2574-1241}

DOI: 10.26717/BJSTR.2021.33.005414

VV Vlasyuk. Biomed J Sci \& Tech Res

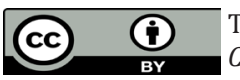

This work is licensed under Creative Commons Attribution 4.0 License

Submission Link: https://biomedres.us/submit-manuscript.php
3. Sinha P, Dutta A, Langford K (2010) Instrumental delivery: how to meet the need for improvements in training. The Obstetrician \& Gynaecologist 12: 265-271.

4. Vlasyuk VV (2009) Birth trauma and perinatal disorders of cerebral circulation. Nestor-History, St. Petersburg, Russia.

5. Vlasyuk VV (2019) Birth Trauma and Perinatal Brain Damage. Springer International Publishing, Springer Nature Switzerland AG.

6. Mochalova MN, Ponomareva Yu N, Mudrov VA (2015) Features of the configuration of the head at birth large fruit. Modern problems of science and education p. 3.

7. Vlasyuk VV (2019) Compression circulatory hypoxia of the brain as a type of intrapartum hypoxia. J Gynecol 4(1): 000173.

8. Heyborne KD (2017) A Systematic review of intrapartum fetal head compression: what is the impact on the fetal brain? AJP Rep 7(2):79-85.

9. Zirakadze AN, Kintraya PY (1983) Experimental analysis of the value of methods for monitoring the functional state of the fetus during labor. On Sat scientific proceedings of the Research Institute of Perinatal Medicine. Obstetrics and Gynecology of the Ministry of Health of the Georgian SSR Tbilisi p. 3-9.

10. Lindgren $L$ (1977) The influence of pressure upon the fetal head during labour. Acta Obstet Gynecol Scand 56(4): 303-309.

11. Muller D (1973) Die subakuten Massenverschiebungen des Gehirns unter der Geburt. Leipzig: VEB Georg Thieme.

12. Vlasyuk VV (2019) Birth Trauma and Compensatory-adaptive Mechanisms at the Head Configuration (Molding). Journal of Gynaecology and Paediatric Care 1(1): 1-7.

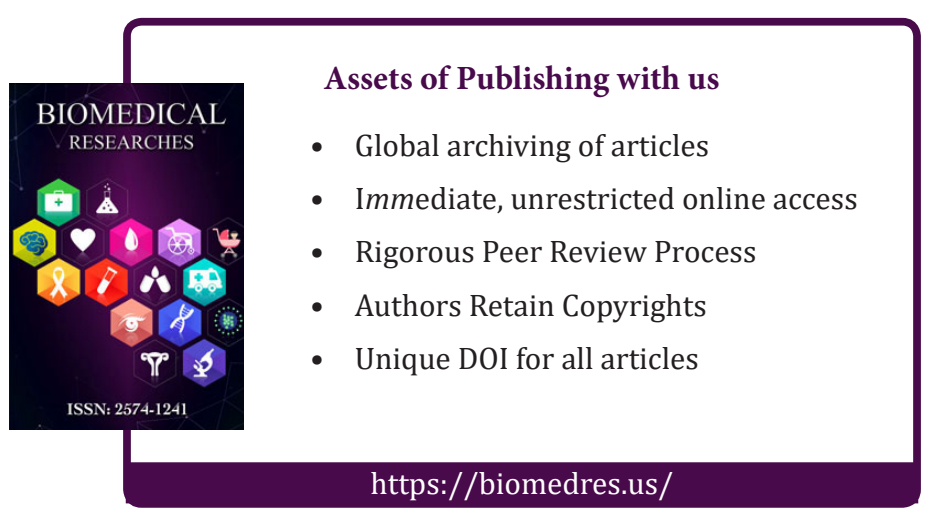

